\title{
The Investigation of Laser Lap Welding Process on High-Strength Galvanized Steel Sheets
}

\author{
Shiquan Zhou, ${ }^{1}$ Yi Zhao, ${ }^{1}$ Zhenguo Peng, ${ }^{2}$ and Fangjie Ren ${ }^{1}$ \\ ${ }^{1}$ Industrial Center, Huazhong University of Science and Technology, Wuhan 430074, China \\ ${ }^{2}$ Technology Center, Dongfeng Automobile Limited Company, Wuhan 430068, China
}

Correspondence should be addressed to Shiquan Zhou, zhousqwq@163.com

Received 12 January 2011; Accepted 16 February 2011

Academic Editor: Y. Zhang

Copyright (c) 2011 Shiquan Zhou et al. This is an open access article distributed under the Creative Commons Attribution License, which permits unrestricted use, distribution, and reproduction in any medium, provided the original work is properly cited.

\begin{abstract}
The development of automobile steel was analyzed in this paper; it is pointed out that high-strength galvanized steel will be widely used in the car body structure. By analyzing welding problems about the dual phase (DP) series of high-strength galvanized steel, the importance of laser welding was concerned. Finally, laser lap welding process technology of high-strength galvanized steel was studied; the results show that the lap weld with welding process smooth and spatter-free as well as beautiful welding bead surface appearance and good mechanical properties can be made by using the dual-beam laser welding technology and interlayer for welding high-strength galvanized steel.
\end{abstract}

\section{Introduction}

Automotive performance is developing to the direction for lower fuel consumption, safety, and durability. This requires the vehicle weight to be reduced, strength of the materials to be improved, and atmospheric corrosion resistance to be better.

When the sheet thickness is reduced from $1.5 \mathrm{~mm}$ to $1.0 \mathrm{~mm}$, the vehicle weight will drop $15-30 \%$; therefore, in the present and future for a long time, the development trend of automobile production will be to reduce sheet thickness, which will inevitably lead to increased mechanical properties of steel sheet.

It can be seen from Figure 1 that the strength level of steel early used in automobile mostly is located in the 300 $400 \mathrm{MPa}$ mainly including IF, Mild, BH, and CMn steel, because of their lower strength; usually steel thickness is between $1.2-1.5 \mathrm{~mm}$, so, the vehicle weight is increased, vehicle fuel performance is dropped. After 1990's, the worldwide energy crisis resulted in the demand of low fuel consumption cars continuously increased, vehicle lightweight has been the developing direction of new type cars [1].

First of all, the United States and Canada in 2000 set up a special research organization "Auto21", the organization started 5 years research plan of vehicle lightweight. In the high-strength steel vehicle, the application of DP and TRIP steels in vehicle body structure was mainly studied [2]. Steel sheet thickness decreases to $0.7-1.0 \mathrm{~mm}$, and to ensure good corrosion resistance, they were usually hot dip Galvanized steel sheets and Galvan annealed steel sheets. However, the zinc coating influence the welding performance seriously; resistance welding process commonly used in car body production is difficult to ensure good quality of welding due to the corrosion of zinc on the copper electrodes which leads to premature failure of electrodes. Spatter caused by zinc evaporation of weld leads to unstable weld performance [3]. By investigation of laser welding of butt joints, a very small heat affected zone and high weld performance as well as no stamping cracking after laser welding were found [4]. Therefore, laser welding of high-strength galvanized steel has been applied in the Welding-Stamping structure of doors and other car parts early [5]. Because of requiring very high assembly quality in laser butt welding, most of the body structure still uses overlap structure. When laser welding of high-strength galvanized steel lap weld, the rapid evaporation of zinc coating in the faying surfaces of the sheets is caused due to high speed of the laser heating, which leads to a few atmospheres pressure formed between the two sheets. Once the upper sheet is melted, the high-pressure zinc steam will be suddenly exploded which results in weld metal 
spattering, porosity and other defects, weld performance degradation, deterioration of the quality appearance.

To prevent spattering in laser lap welding of the high strength galvanized steel, researchers use a variety of techniques; these include mechanical assembly method which means $0.1-0.2 \mathrm{~mm}$ gap in the welding bead is reserved by using shims as the lap joint is assembled, so that zinc vapor can escape through the gap [6,7]. But for the $1 \mathrm{~mm}$ sheets, to ensure the stability of $0.1-0.2 \mathrm{~mm}$ gap is difficult, so mechanical assembly method can only be used for thick plate. Keyhole welding which means that Zinc vapor escapes through the Keyhole formed by laser beam [8, 9]; however, because of high zinc vapor pressure, the liquid metal near the Keyhole will often be taken away, which causes weld porosity. Dual beam laser welding which means that Zinc vapor escapes through the first low-power laser beam makes the galvanized layer between the two faying surface vaporized only, but the upper sheet does not melt, and then the two sheets are welded with subsequent high-power laser beam $[10,11]$. Although there is, almost no gap between the two faying surfaces, the Zinc vapour does not escape from the faying surface after zinc coating melted and vaporized, only migration and precipitation occur towards the direction of weld; the Zinc will generate secondary evaporation under the thermal effect of high-power laser beam which leads to spattering. The process such as $\mathrm{Al}$ foil as the interlayer [12]: melting temperature (MT) of $\mathrm{Al}$ is $660^{\circ} \mathrm{C}$, the boiling temperature (BT) of $\mathrm{Zn}$ is $907^{\circ} \mathrm{C}$, Al's BT is $2450^{\circ} \mathrm{C}$, so that when $\mathrm{Al}$ is melted, $\mathrm{Zn}$ is not evaporated and form liquid Al-Zn alloy with liquid Al. When the alloy boiling temperature $(\mathrm{BT}=2450 \times \mathrm{Al} \%+907 \times \mathrm{Zn} \%)$ is greater than $1500^{\circ} \mathrm{C}$, evaporation of zinc coating can be prevented with no spattering, but the mechanical performance of joint is declined. Because of the too fast laser heating, $\mathrm{Zn}$ has been evaporated before being dissolved into the $\mathrm{Al}$, which leads to the need of more liquid $\mathrm{Al}$ to accommodate $\mathrm{Zn}$ vapor; the thickness of Al foil interlayer reaches $75 \mu \mathrm{m}$, so the aluminum content dissolved into welding pool is high which leads to a decrease in the mechanical performance. So far spattering problem can be solved only by shaving out zinc coating for laser lap welding of high strength galvanized steel sheet [13]; weld corrosion resistance will be declined after Zinc coating is cut out. Therefore, the purpose of this paper is to ensure good weld corrosion resistance, appearance, and mechanical properties for lap welding of high-strength galvanized steel sheets by using dual beam laser and interlayer process.

\section{Experimental Procedures}

A continuous wave $\mathrm{CO}_{2}$ laser, power $4 \mathrm{KW}$, wavelength $10.6 \mu \mathrm{m}$, the laser output mode TEM00, focal length $150 \mathrm{~mm}$, focal diameter $0.2-0.3 \mathrm{~mm}$ were used in this experiment.

DP600 galvanized steel sheets with thickness of $1 \mathrm{~mm}$ were used; the sample size and the welding joint form are shown in Figure 2. Al foil thickness of $25 \mu \mathrm{m}$ can be found in Figure 2, high- and low-power laser beam were obtained by, respectively, welding methods; $\mathrm{Al}$ and $\mathrm{Zn}$ interlayer were

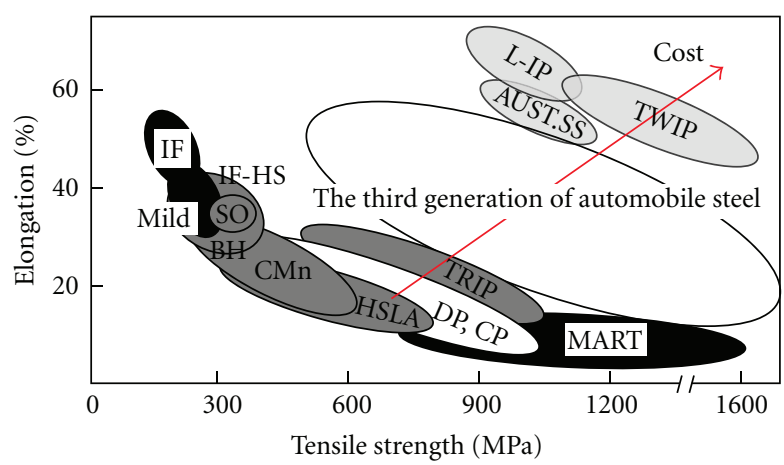

Figure 1: Properties and cost of steels.

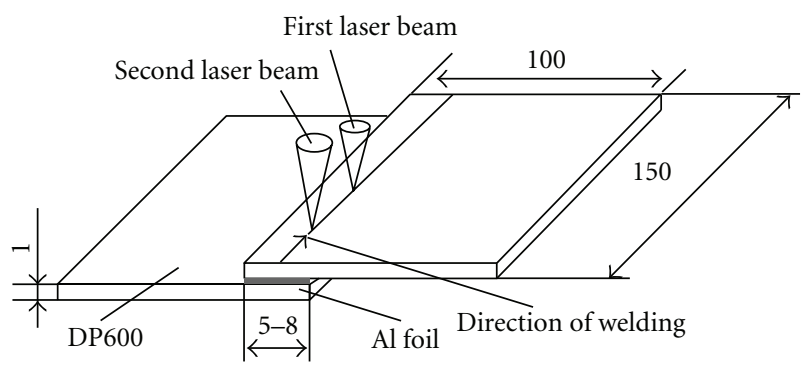

Figure 2: Schematic of welding samples.

TABLE 1: Welding experiment plan.

\begin{tabular}{lccc}
\hline No. & $\begin{array}{c}\text { Interlayer thickness } \\
(\mu \mathrm{m})\end{array}$ & $\begin{array}{c}\text { First laser beam } \\
\text { power }(\mathrm{KW})\end{array}$ & $\begin{array}{c}\text { Second laser beam } \\
\text { power }(\mathrm{KW})\end{array}$ \\
\hline 1 & 0 & 2 & 0 \\
2 & 0 & 0 & 4 \\
3 & 0 & 2 & 4 \\
4 & 25 & 2 & 0 \\
5 & 25 & 0 & 4 \\
6 & 25 & 2 & 4 \\
7 & 50 & 2 & 0 \\
8 & 50 & 2 & 4 \\
9 & 50 & 0 & 4 \\
10 & 75 & 0 & 4 \\
11 & 75 & 2 & 4 \\
\hline
\end{tabular}

melted and alloyed with $2 \mathrm{KW}$ power laser beams at the beginning, and then $4 \mathrm{KW}$ power laser beam was used for welding; weld depth was required not to be less than $1.5 \mathrm{~mm}$. Welding speed was kept in $7 \mathrm{~m} / \mathrm{min}$ and welding experiment program is shown in Table 1.

In accordance with Table 1 of the welding experimental methods, each experiment was repeated five times. Before and after welding the specimen was weighed with analytical balance in order to analyze the size of spattering. Then the three specimens after welding were tested tensile shear load with tensile machine. Specimen fracture, microstructure, and microarea composition were analyzed by using Phillips field scanning electron microscope. 


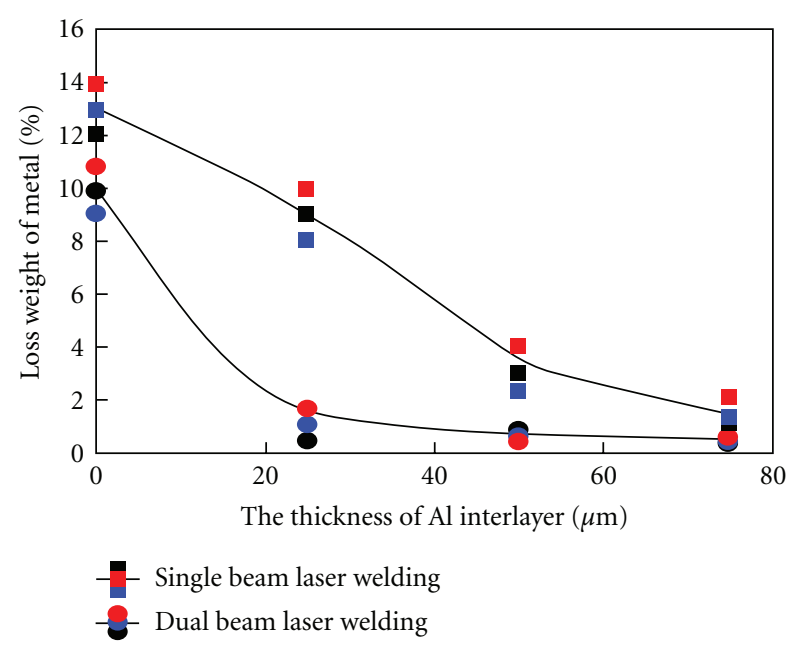

FIgURE 3: The weld metal loss versus the thickness of $\mathrm{Al}$ interlayer.

\section{Experimental Results and Discussion}

The relationship between the thickness of aluminum interlayer and the weight loss produced due to spattering in single- and dual-beam laser welding is plotted in Figure 3. The figures show that the spattering rates of two laser weldings are very high without the aluminum interlayer. There are many spatters near weld bead that can be seen in Figure 4(a), which is the results from evaporation of zinc leads to spattering and metal is brought out molten pool. With the increase of aluminum interlayer thickness, the two laser welding spatter rate decreases, but the spattering can be inhibited basically just with $25-\mu \mathrm{m}$-thick aluminum foil in dual beam laser welding, for example, no spatters can be found in Figure 4(b).

The relationship between aluminum interlayer thickness and tensile shear load per unit length is shown in Figure 5 for single and dual beam laser welding joints. It can be seen that the tension shear loads are very low without aluminum interlayer in both single and dual beam laser welding joints; because of spattering and holes causing reduction of bearing area, the hole and weld depression can be seen clearly in Figure 6 . When the aluminum interlayer thickness is $25 \mu \mathrm{m}$, the tensile shear load of unit length is larger disparity for single beam laser welding joint, the average of tensile shear load per unit length is reduced $200 \mathrm{~N} / \mathrm{mm}$ comparing to tensile shear load per unit length of dual beam laser welding joints, tensile shear fracture occurs in the base metal for dual beam laser welding joints (see Figure 7(a)); when the thickness of aluminum interlayer is greater than $25 \mu \mathrm{m}$, the tensile shear load of unit length falls. Continuously, the shear fracture locates in the weld (see Figure $7(b)$ ). Therefore, although the increase of aluminum interlayer thickness can reduce the spattering, tensile shear load of the joints also drops down. In accordance with the reference [14], loss leaded by the weld metal spatter is more than $4 \%$, the welding quality is unacceptable. Therefore, analyzing the two respects of reducing spattering and improving the joint performance,
TABle 2: EDX of microcomposition in Figure 8(a).

\begin{tabular}{lcccc}
\hline No. & $\mathrm{Al}(\mathrm{at} \%)$ & $\mathrm{Mn}(\mathrm{at} \%)$ & $\mathrm{Fe}(\mathrm{at} \%)$ & $\mathrm{Zn}(\mathrm{at} \%)$ \\
\hline 1 & 61.93 & 0.73 & 27.52 & 9.82 \\
2 & 30.13 & 0.69 & 6.68 & 62.51 \\
3 & 35.89 & 0 & 3.32 & 60.79 \\
4 & 62.44 & 0 & 27.56 & 9.99 \\
\hline
\end{tabular}

only the dual beam laser welding with $25 \mu \mathrm{m}$ aluminum interlayer can get the best results.

3.1. Effects of Aluminum Interlayer. The main object of using aluminum interlayer is to melt aluminum and zinc in order to form zinc-aluminum alloy after laser heating; when the alloy composition meets BT $=2450 \times \mathrm{Al} \%+907 \times \mathrm{Zn} \%>$ $1500^{\circ} \mathrm{C}$, it is possible to prevent the evaporation of zinc so as to Inhibit spattering and porosity; the calculation shows that when aluminum content of the alloy is larger than $38.4(\mathrm{at} \%)$ or 20 (wt\%), the BT of the zinc-aluminum alloy will reach more than $1500^{\circ} \mathrm{C}$. Usually the thickness of zinc coating is about $10 \mu \mathrm{m}$, the thickness of aluminum interlayer is calculated as $26.5 \mu \mathrm{m}$ by

$$
\delta_{\mathrm{Al}}=10 \frac{\rho_{\mathrm{Zn}}}{\rho_{\mathrm{Al}}}=10 \frac{7.15}{2.7}=26.5 \mu \mathrm{m} .
$$

However, in the melting process, the iron tends to dissolve into the $\mathrm{Al}-\mathrm{Zn}$ alloy, so the actual thickness of aluminum foil will be less than $26.5 \mu \mathrm{m}$. Therefore, as long as the thickness is $25 \mu \mathrm{m}$ aluminum foil can prevent the evaporation of zinc. The microstructure between the two sheets faying surfaces can be seen in Figure 8(a) by using low-power laser beam; EDS composition analysis in Table 2 shows that the faying surface has become a $\mathrm{Zn}-\mathrm{Al}-\mathrm{Fe}$ alloy; the atomic percentage of zinc is about $60-63 \%$ and the atom percentage of aluminum + iron is about $37-40 \%$. Therefore BT has been more than $1500^{\circ} \mathrm{C}$, when highpower laser welding zinc cannot be evaporated, while very little aluminum content is dissolved into weld pool. This guarantees that the microstructures of weld is composed of the bainite and strip martensite (Figure 9(a)), and the weld strength is higher than the base metal, so that fracture occurs at the base metal, the fracture is ductile hole features (Figure 10(a)), tensile shear load reaches maximum.

When the $\mathrm{Al}$ interlayer thickness is $50 \mu \mathrm{m}$, the $\mathrm{Al}-\mathrm{Fe}$ intermetallic compounds are still formed near the steel sheet, but in the central part of the interlayer the atomic percentage of aluminum + iron is up to $82-88 \%$ (Figure $8(\mathrm{~b})$ and Table 3). Despite the BT increases to $1900^{\circ} \mathrm{C}$, there is a lot of aluminum in the interlayer, when the high-power laser welding is coming, the aluminum will enter the weld pool which leads to increase in the aluminum content in weld and to a drop in mechanical performance of weld.

Ductile hole features are found during analyzing specimens fractures of $25 \mu \mathrm{m}$ aluminum interlayer; after dual beam laser welding (Figure 9(a)), fracture occurs in the base metal (Figure $7(\mathrm{a})$ ). The weld microstructures are composed of bainite and strip martensite (Figure 9(b)). 


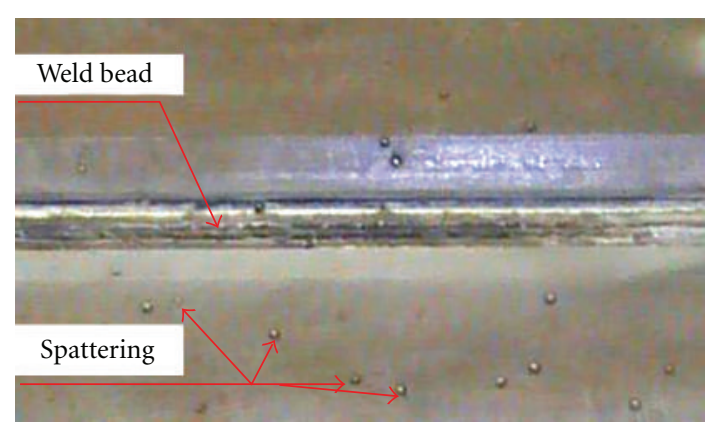

(a)

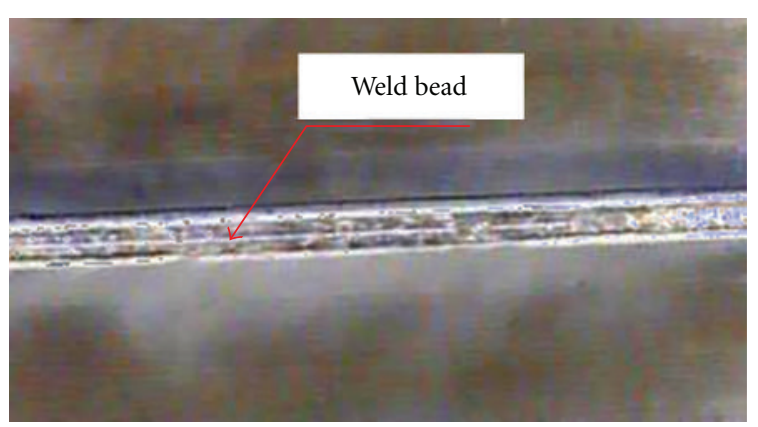

(b)

FIgURE 4: Metal spattering (a) without $\mathrm{Al}$ interlayer and (b) with $25 \mu \mathrm{m}$ Al interlayer.

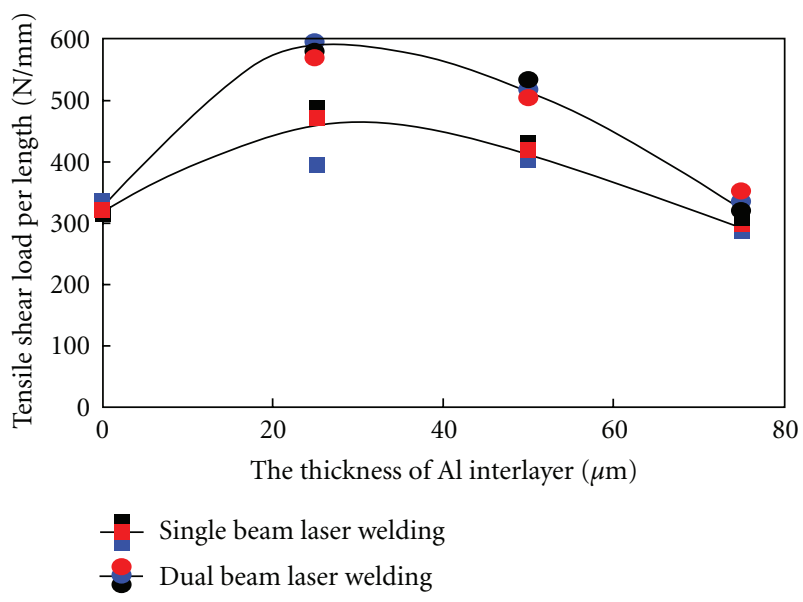

FIGURE 5: Tensile-shear load with 4 KW single laser beam welding.

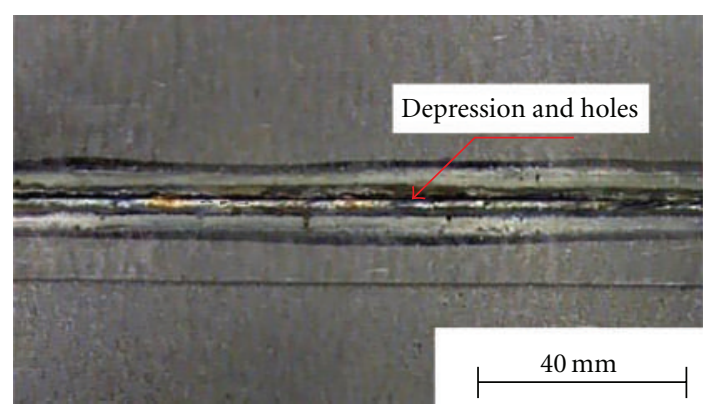

FIGURE 6: Depression and holes in weld without $\mathrm{Al}$ interlayer.

Because the small amount of aluminum will be conducive to the formation of bainite [9], therefore the mechanical performance is higher than the base material of ferrite and martensite.

Intergranular and transgranular fracture can be observed in the specimens of $50 \mu \mathrm{m}$ aluminum interlayer after dual beam laser welding (Figure 10(a)); fracture occurs at the weld fusion zone (Figure 7(b)); the microstructures of the weld are composed of high aluminum ferrite (Figure 10(b), marked
TABLE 3: EDX of microcomposition in Figure 8(b).

\begin{tabular}{lcccc}
\hline No. & $\mathrm{Al}(\mathrm{at} \%)$ & $\mathrm{Mn}(\mathrm{at} \%)$ & $\mathrm{Fe}(\mathrm{at} \%)$ & $\mathrm{Zn}(\mathrm{at} \%)$ \\
\hline 1 & 63.58 & 0 & 26.78 & 9.65 \\
2 & 84.68 & 0 & 3.17 & 12.15 \\
3 & 85.42 & 0 & 1.33 & 13.24 \\
4 & 84.08 & 0 & 3.54 & 12.38 \\
5 & 81.32 & 0 & 0.97 & 17.70 \\
6 & 72.43 & 0 & 20.13 & 7.44 \\
7 & 64.73 & 0.52 & 26.90 & 7.86 \\
\hline
\end{tabular}

Table 4: Micro composition in Figure 11.

\begin{tabular}{lcccc}
\hline No. & $\mathrm{Al} \mathrm{(at} \%)$ & $\mathrm{Mn}($ at $\%)$ & $\mathrm{Fe}($ at $\%)$ & $\mathrm{Zn}($ at $\%)$ \\
\hline 1 & 0 & 0 & 3.96 & 96.04 \\
2 & 0 & 0 & 5.35 & 94.65 \\
3 & 0 & 0 & 38.83 & 61.17 \\
4 & 0 & 0 & 3.96 & 96.04 \\
\hline
\end{tabular}

3), Fe-Al phase (Figure 10(b), marked 1 and 2), and bainite (Figure 10(b), the white phase). The mechanical properties are less than the base metal of ferrite and martensite.

If there is no aluminum interlayer, dual beam laser cannot inhibit the evaporation of zinc. Because after the first low power laser beam heating, the zinc vapor does not escaped from the two sheets faying surfaces; the zinc vapor will immediately condense into zinc alloy after the laser beam leaves. Figure 11 and Table 4 show that zinc vapor condenses in the two sheets faying surfaces; Zn composition increases up to 96 at\%, so while high power laser beam arrives, zinc evaporation and pool spattering will occur again.

Therefore, only using $25 \mu \mathrm{m}$ aluminum interlayer with dual beam laser welding, zinc evaporation can be prevented, the mechanical properties of welds can be improved, and the corrosion resistance of welds can be ensured.

3.2. Effects of Dual Beam Laser. Due to the high speed of the laser heating, if $4 \mathrm{KW}$ high power laser beam is used 


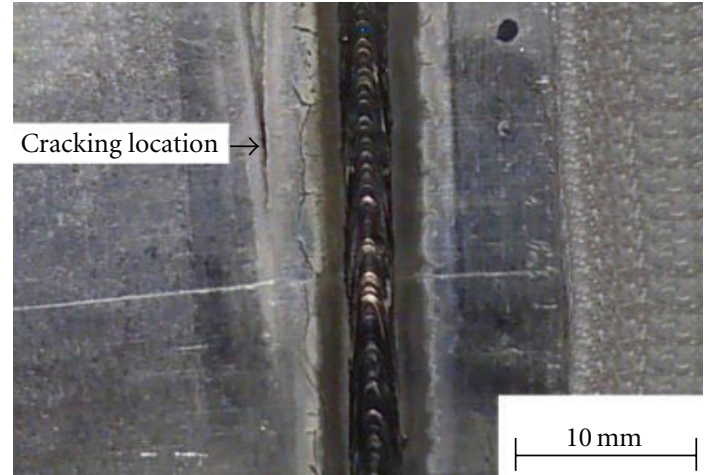

(a)

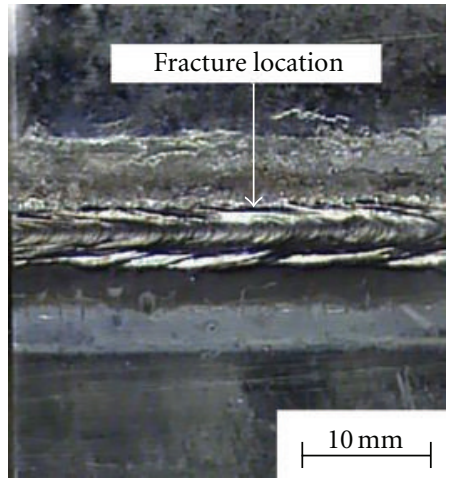

(b)

Figure 7: Dual laser beam welding (a) with $25 \mu \mathrm{m} \mathrm{Al}$ interlayer and (b) with $50 \mu \mathrm{m} \mathrm{Al}$ interlayer.

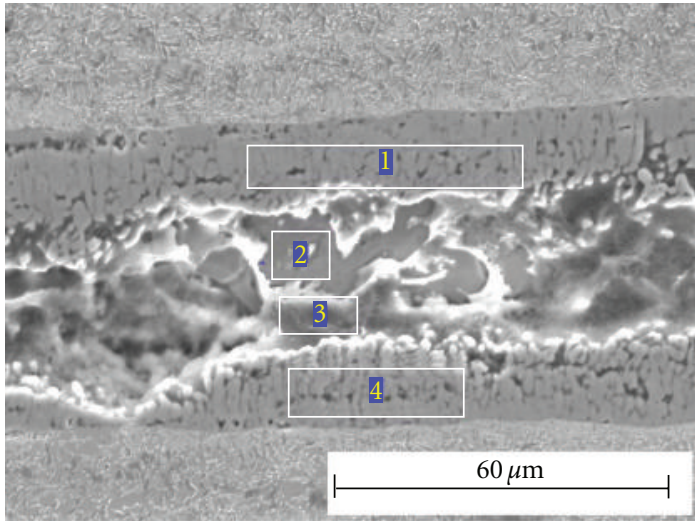

(a)

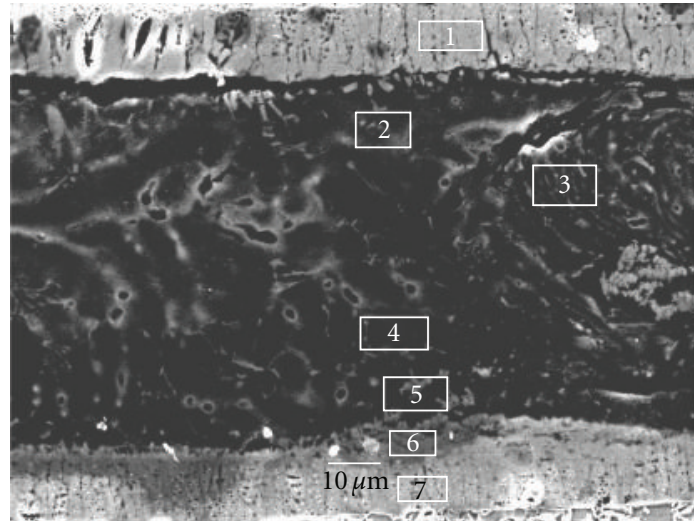

(b)

Figure 8: The microstructure of weld heated by Low power laser beam (a) with $25 \mu \mathrm{m} \mathrm{Al}$ interlayer (b) with $50 \mu \mathrm{m} \mathrm{Al}$ interlayer.

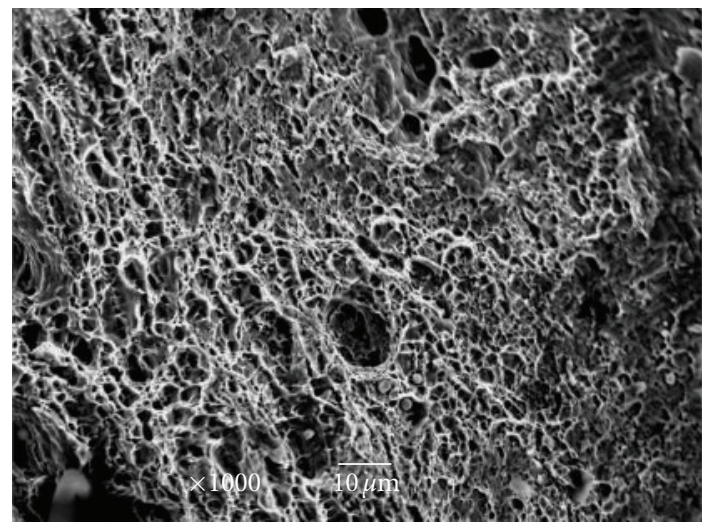

(a)

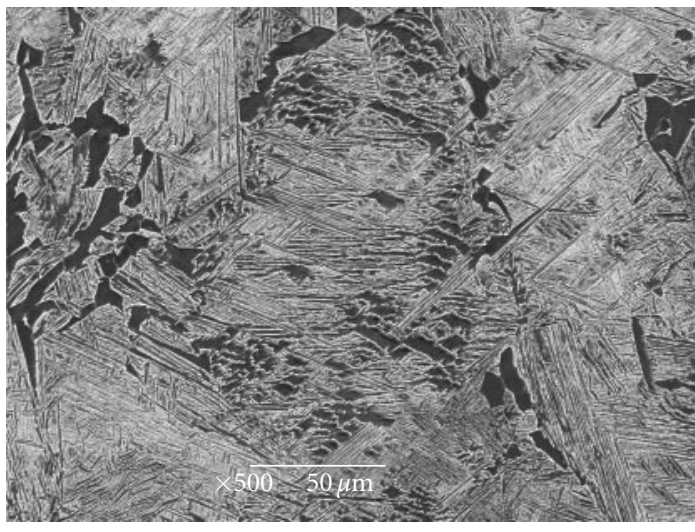

(b)

Figure 9: Joint welded by dual beam laser with $25 \mu \mathrm{m} \mathrm{Al}$ interlayer (a) the tensile-shear fracture. (b) The microstructure of weld.

directly to heat $1 \mathrm{~mm}$ sheet, the temperature of the two sheets faying surfaces will reach $1500^{\circ} \mathrm{C}$ within 0.01 seconds; in such a short time, aluminum and zinc cannot be melted each other. Therefore, the zinc will be still fast evaporated. But because there is the liquid aluminum in the faying surface, so when there is sufficient amount of liquid aluminum, the zinc vapor was pressed into the liquid aluminum near the weld; thus the spattering is prevented [15]. But too much liquid aluminium is added to the weld pool, so that the microstructures of weld are composed of high aluminum 


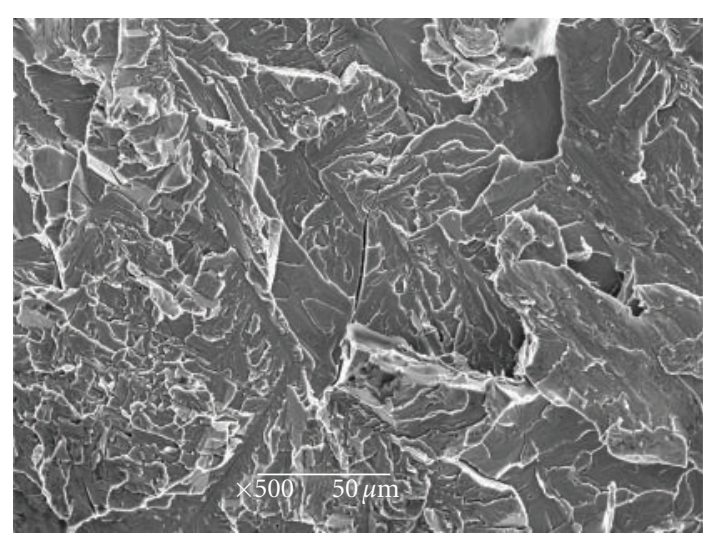

(a)

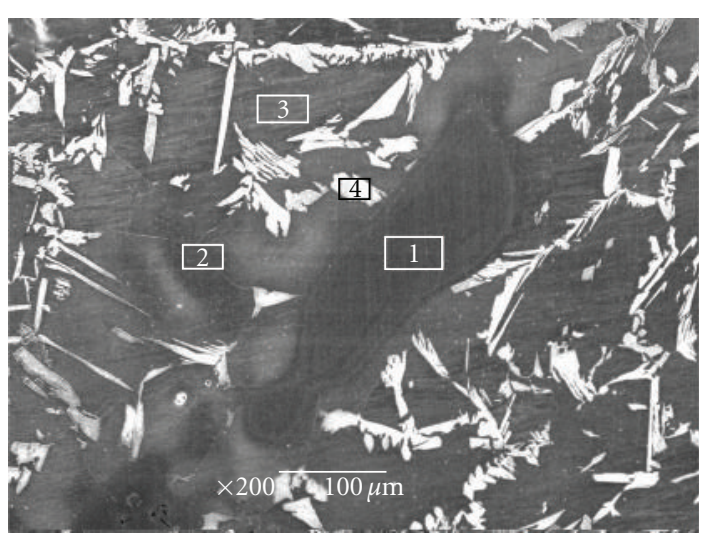

(b)

FIGURE 10: Joint welded by dual laser beam with $50 \mu \mathrm{m} \mathrm{Al}$ interlayer: (a) the tensile-shear fracture, (b) the microstructure of weld.

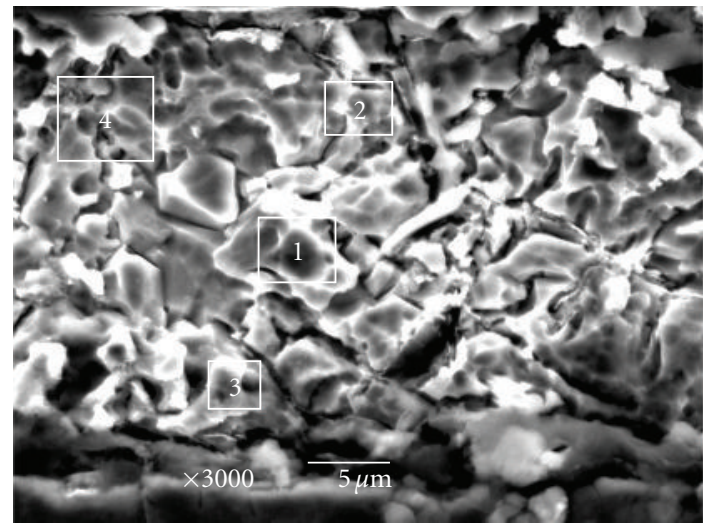

Figure 11: The microstructure of faying surface heated by single laser beam without $\mathrm{Al}$ interlayer.

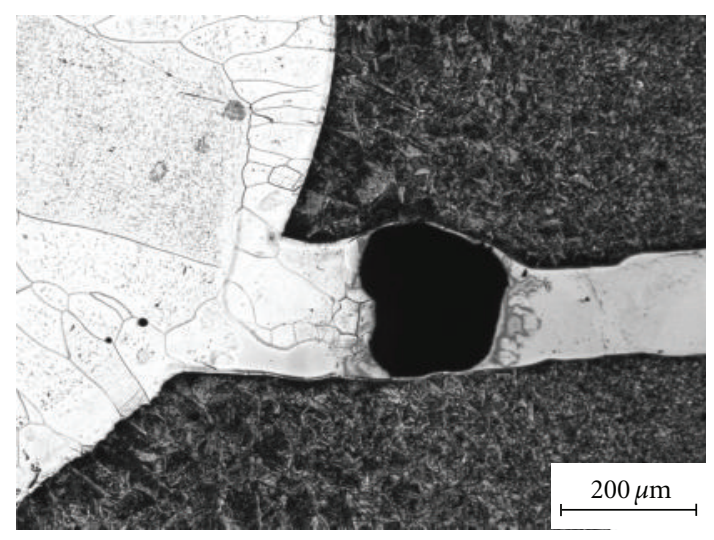

Figure 12: Zinc vapor hole in interlayer near weld.

ferrite and $\mathrm{Fe}-\mathrm{Al}$ intermetallic compounds; therefore, the mechanical properties of weld is dropped down. Microstructures of welded joint cross-section are shown in Figure 12 by using $75 \mu \mathrm{m}$ aluminum interlayer after $4 \mathrm{KW}$ laser beam direct welding; white areas are high aluminum phase in the figure, the zinc pore is located near weld in the faying surface. Therefore, in the single beam laser welding, when the aluminum interlayer thickness is less than $50 \mu \mathrm{m}$, the weld metal suffers serious losses due to spattering, while the aluminum interlayer thickness greater than $50 \mu \mathrm{m}$, the weld metal spattering been inhibited, but the aluminum content in the weld metal is too high, which leads to reduce welded joint tensile shear load.

When using dual-beam laser heating, $2 \mathrm{KW}$ low power laser can only heat the two sheets faying surfaces to 700$900^{\circ} \mathrm{C}$; during this time, aluminum and zinc are being melted; there is no evaporation of zinc, so aluminum and zinc can be formed into zinc-aluminum alloy so as to increase its BT. When the aluminum interlayer thickness is $25 \mu \mathrm{m}$, the BT of zinc-aluminum alloy has been greater than $1500^{\circ} \mathrm{C}$, so when $4 \mathrm{KW}$ high power laser arrived, there was no zinc vapor generation; the loss of the weld metal spattering is prevented; weld appearance is smooth and clean; at the same time, the aluminum content in the weld metal is low (less than $1.5 \mathrm{wt} \%$ ), the morphology of joint appearance as well as the cross-section is shown in Figure 13. This leads to increase in the tensile shear load of welded joints.

\section{Conclusion}

(1) The spattering caused by zinc evaporation can be inhibited by using aluminum interlayer and dual beam laser welding so as to ensure high mechanical properties of welded joints.

(2) When power of the first laser beam is $2 \mathrm{KW}$, power of second laser beam is $4 \mathrm{KW}$, welding speed is $7 \mathrm{~m} / \mathrm{min}$, and interlayer thickness is $25 \mu \mathrm{m}$; the weld metal spatter can be controlled less than $1 \%$ and the welded joint tensile shear load per length can reach $610 \mathrm{~N} / \mathrm{mm}$.

(3) First laser beam is mainly used to melt the aluminum interlayer and zinc coating so as to form zinc-aluminum alloy. 


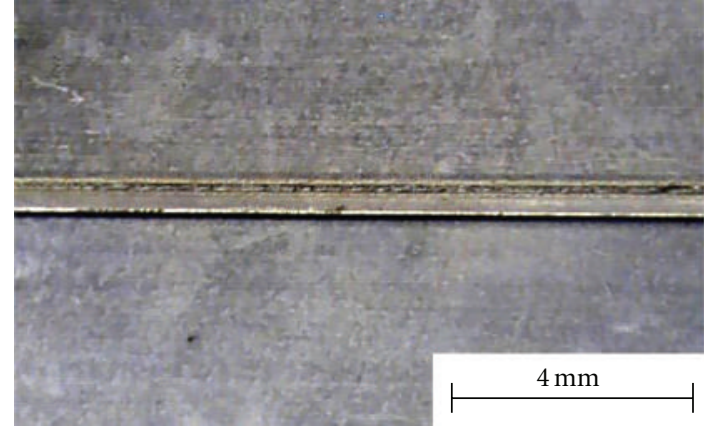

(a)

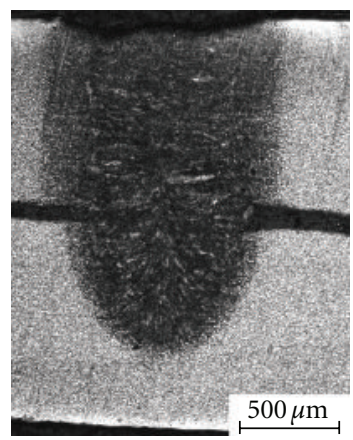

(b)

FIGURE 13: Dual laser beam welding with $25 \mu \mathrm{m} \mathrm{Al}$ interlayer: (a) Surface of weld, (b) Cross-section of weld.

(4) If aluminum interlayer thickness is greater than $50 \mu \mathrm{m}$, aluminum content of the weld will increase; microstructures of the weld are composed of high aluminum ferrite and $\mathrm{Fe}-\mathrm{Al}$ intermetallic compounds.

\section{Acknowledgment}

The authors acknowledge the support from Dongfeng Automobile Limited Company for the experiments of the paper.

\section{References}

[1] J. Li and R. Qiu, "The investigation of high strength steel for car body and processing performance," Technology and Materials of Automobile, vol. 2, pp. 49-52, 2010.

[2] Research funding of Canada government, "Auto21(W)," http://www.auto21.ca/.

[3] R. Akhter, "The nature of the $\mathrm{Zn}$ vapour problem and a variety of potential strategies for mitigating it," in Proceedings of the 5th International Conference, pp. 195-206, 1988.

[4] M. S. Xia, M. L. Kuntz, Z. L. Tian, and Y. Zhou, "Failure study on laser welds of dual phase steel in formability testing," Science and Technology of Welding and Joining, vol. 13, no. 4, pp. 378-387, 2008.

[5] Q. Yan and R. Guo, "Finite element simulation and experimental study of stamping on laser welding door panel," China Laser, vol. 34, no. 1, pp. 242-244, 2007.

[6] Powerlasers Ltd., "Method of laser beam welding of zinccoated steel sheet," Canada Patent CA 2209804, 1999.

[7] Mitsubishi Co., "Laser welding method," U.S. Patent 47455257, 1987.

[8] Magna Int Inc., "Method of laser welding coated members," Canada Patent CA2534251, 2005.

[9] Y. Tzeng, "Gap-free lap welding of zinc-coated steel using pulsed $\mathrm{CO}_{2}$ laser," International Journal of Advanced Manufacturing Technology, vol. 29, no. 3-4, pp. 287-295, 2006.

[10] D. Chrysler, "Laser welding of coated plates in the automotive industry uses one laser to warm and a second one to weld," Germany Patent DE10309157, 2004.

[11] G. Mariana and F. Lu, "Development of advanced dual-beam laser welding head for lap joining of zinc-coated steel sheets without intended gap at the interface," in Proceedings of the 12th Sheet Metal Welding Conference (SMWC '06), Livonia, Mich, USA, May 2006.
[12] X. Li, S. Lawson, Y. Zhou, and F. Goodwin, "Novel technique for laser lap welding of zinc coated sheet steels," Journal of Laser Applications, vol. 19, no. 4, pp. 259-264, 2007.

[13] E. J. Pennington, "Laser welding of galvanized steel," U.S. Patent 4642446, 1985.

[14] R. Fabbro, F. Coste, D. Goebels, and M. Kielwasser, "Study of CW Nd-Yag laser welding of Zn-coated steel sheets," Journal of Physics D, vol. 39, no. 2, pp. 401-409, 2006.

[15] S. Zhou and Z. Peng, "Mechanism of $\mathrm{Zn}$ vapour suppressed by $\mathrm{Al}$ in laser lap welding of high strength zinc coated sheet steel," Applied Mechanics and Materials, vol. 37-38, pp. 634$642,2010$. 

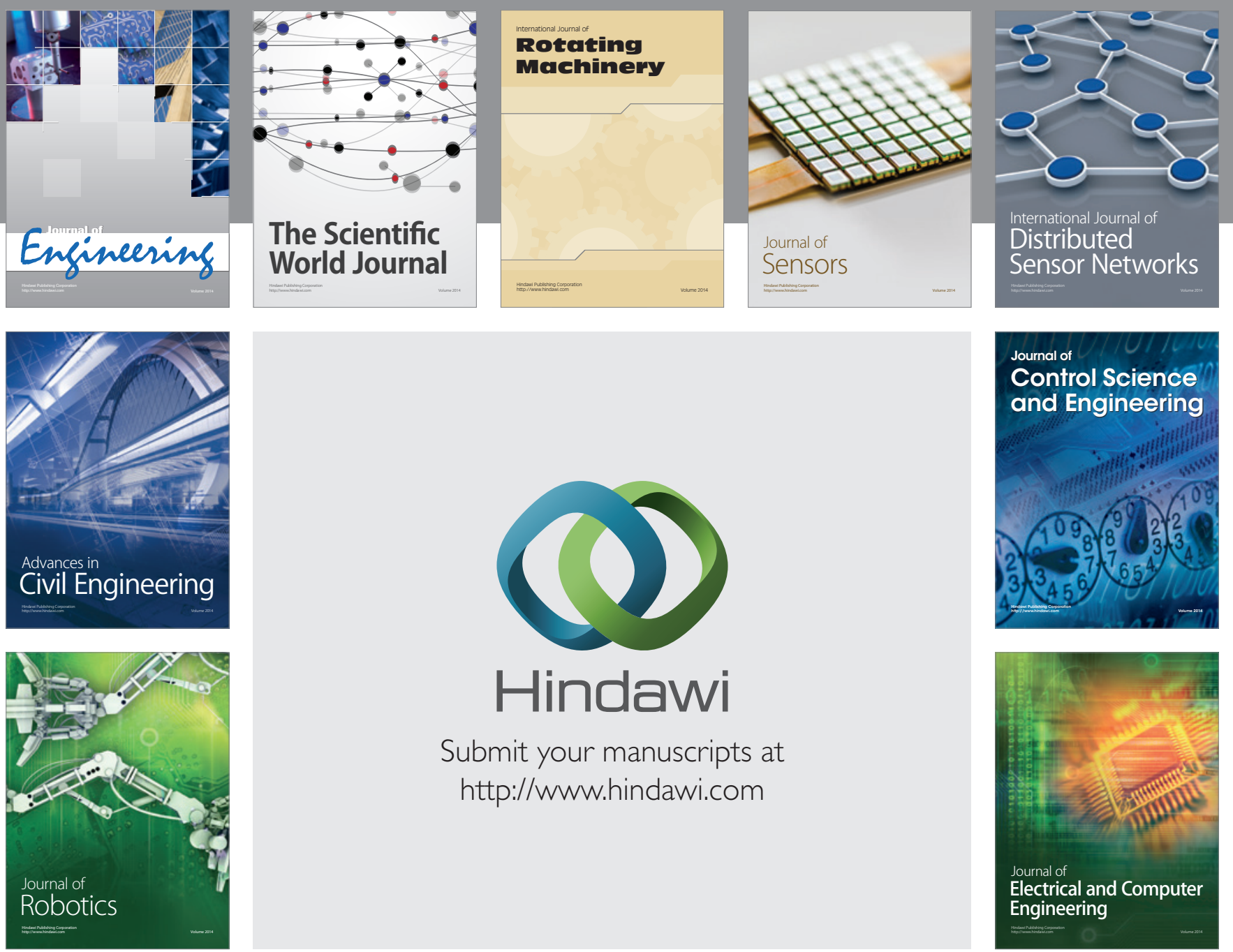

Submit your manuscripts at

http://www.hindawi.com
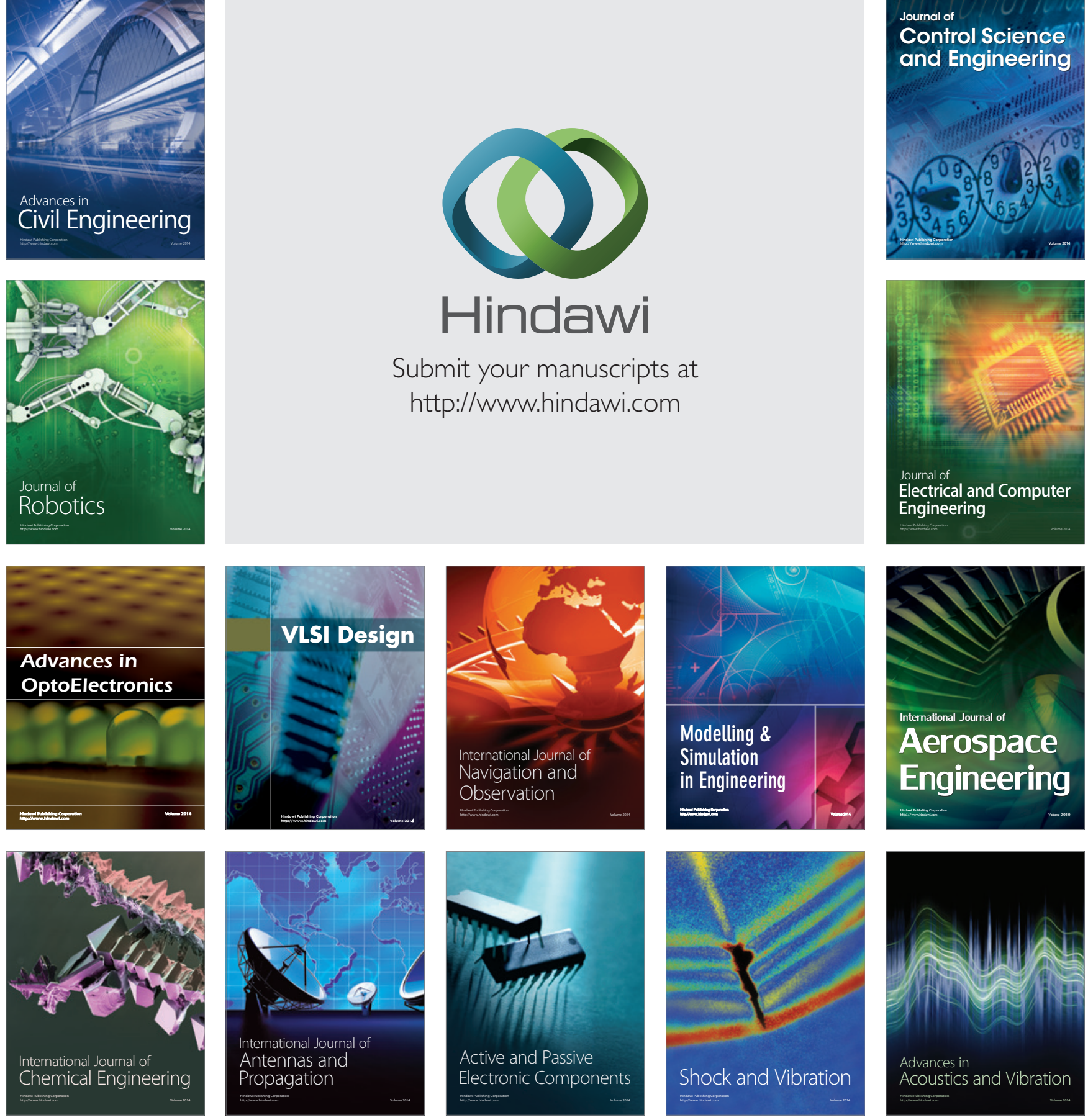